\title{
Computed Tomography Airway Tree Tortuosity Features Predict Functional Small Airway Disease in Chronic Obstructive Pulmonary Disease
}

Daniel Genkin, ${ }^{1}$ Danesh Aslam, ${ }^{1}$ Jason Bartlett, ${ }^{2}$ Harvey Coxson PhD, ${ }^{3}$ Wan C. Tan MD, ${ }^{3}$ James C. Hogg MD, PhD, ${ }^{3}$ Sri Krishnan PhD ${ }^{*}$ and Miranda Kirby PhD ${ }^{*}$

\section{Introduction}

- Over 1,000,000 Canadians are diagnosed with Chronic Obstructive Pulmonary Disease (COPD), and by 2020 the disease will be the third deadliest on Earth ${ }^{1,2}$

- Despite high prevalence, diagnosis of COPD occurs late in the disease course, after a large portion of the small airways are destroyed

- Current methods to quantify small airway disease (SAD) using the Disease Probabilly Measure (DPM) approach requires CT images acquired at full-inspiration and full-expiration, and therefore there are technical challenges and dose concerns

- Computed Tomography (CT) imaging using only a single fulinspiration CT image can be used segment the central airway tree and generate quantitative morphometric measurements

\section{Objective \& Hypothesis}

Objective

To determine if CT airway tortuosity measures can be developed and

re independently associated with DPM SAD

Hypothesis

- We hypothesize that CT measurements reflecting airway tree - Wrtuosity will be significantly correlated with DPM SAD measurements

\section{Methods}

Canadian Cohort Obstructive Lung Disease (CanCOLD)

Cohort between $45-90$ years of age identified by random digit dialing from the general population

fSAD

CT full-inspiration and full-expiration images are registered using deformable image registration, and all voxels are classified as normal, emphysema or SAD. SAD is the percentage of voxels in the lung classified as small airway disease.

Standard Quantitative CT Measurements

Pas defined as the hypothetical wall thickness of an airway with servable airway segments in the airway tree.

ortuosity

- The Straight Distance Tortuosity was defined as the ratio between the total path length of a segment and its straight line distance between the fully straight path.

Table 1. Subject Demographics

\begin{tabular}{|c|c|c|c|c|}
\hline \begin{tabular}{|l|} 
Parameter \\
$( \pm S D$ unless \\
specified)
\end{tabular} & $\begin{array}{c}\text { Never-Smoker } \\
(n=29)\end{array}$ & $\begin{array}{l}\text { At Risk } \\
(\mathrm{n}=166)\end{array}$ & $\begin{array}{l}\text { GOLD I } \\
(n=181)\end{array}$ & $\begin{array}{l}\text { GOLD II+ } \\
(n=175)\end{array}$ \\
\hline \begin{tabular}{|l} 
Age, yrs \\
\end{tabular} & $67(10)$ & $68(9)$ & $71(10)$ & (9) $\ddagger$ \\
\hline F Sex, n (\%) & & & $39(70)^{*}$ & $46(80)$ \\
\hline Pack-years, yrs & $0(0) \dagger \ddagger$ & $21(21)^{*}$ & $17(22)^{*}$ & $24(24)^{*} \ddagger$ \\
\hline $\mathrm{FEV}_{1} / \mathrm{FVC}, \%$ & $75(5) \ddagger$ & $77(5) \ddagger$ & $64(4)^{*}+$ & $58(9)^{*}+\ddagger$ \\
\hline RV/TLC, \% & $41(7)$ & $38(8) \ddagger$ & $41(8) \dagger$ & $48(11)^{*}+7$ \\
\hline BMI & $28(8)$ & $28(5)$ & $27(4)$ & $28(5) \ddagger$ \\
\hline
\end{tabular}
*Significantly different from Never-smoker; †Significantly different from At Risk;

\section{Results}

Healthy Never-Smoker

Air Tree Mask

Straight Distance Tortuosity: $L_{A} / L_{s}$

$$
S D T_{\text {Left Main }}
$$

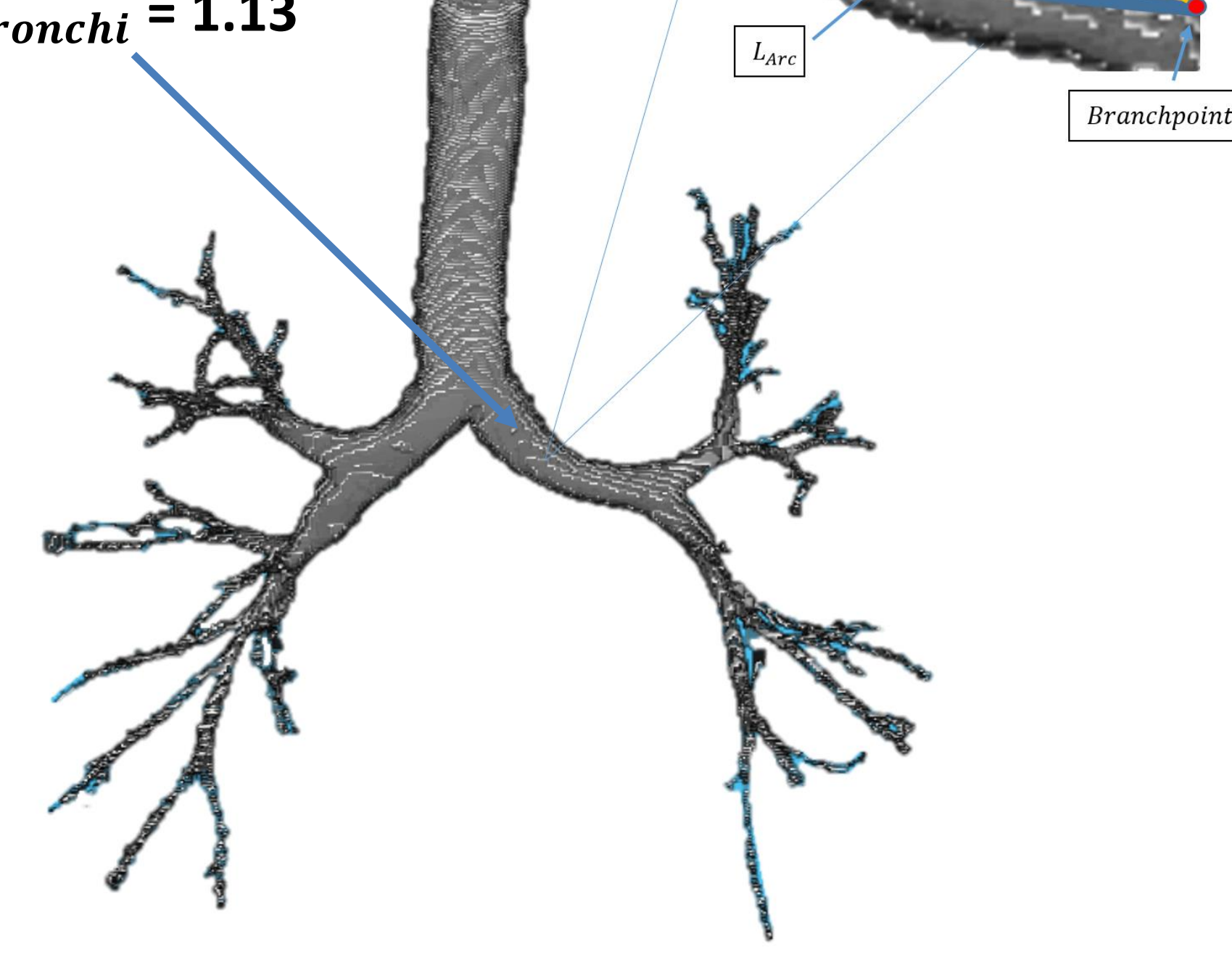

2. DPM Mask
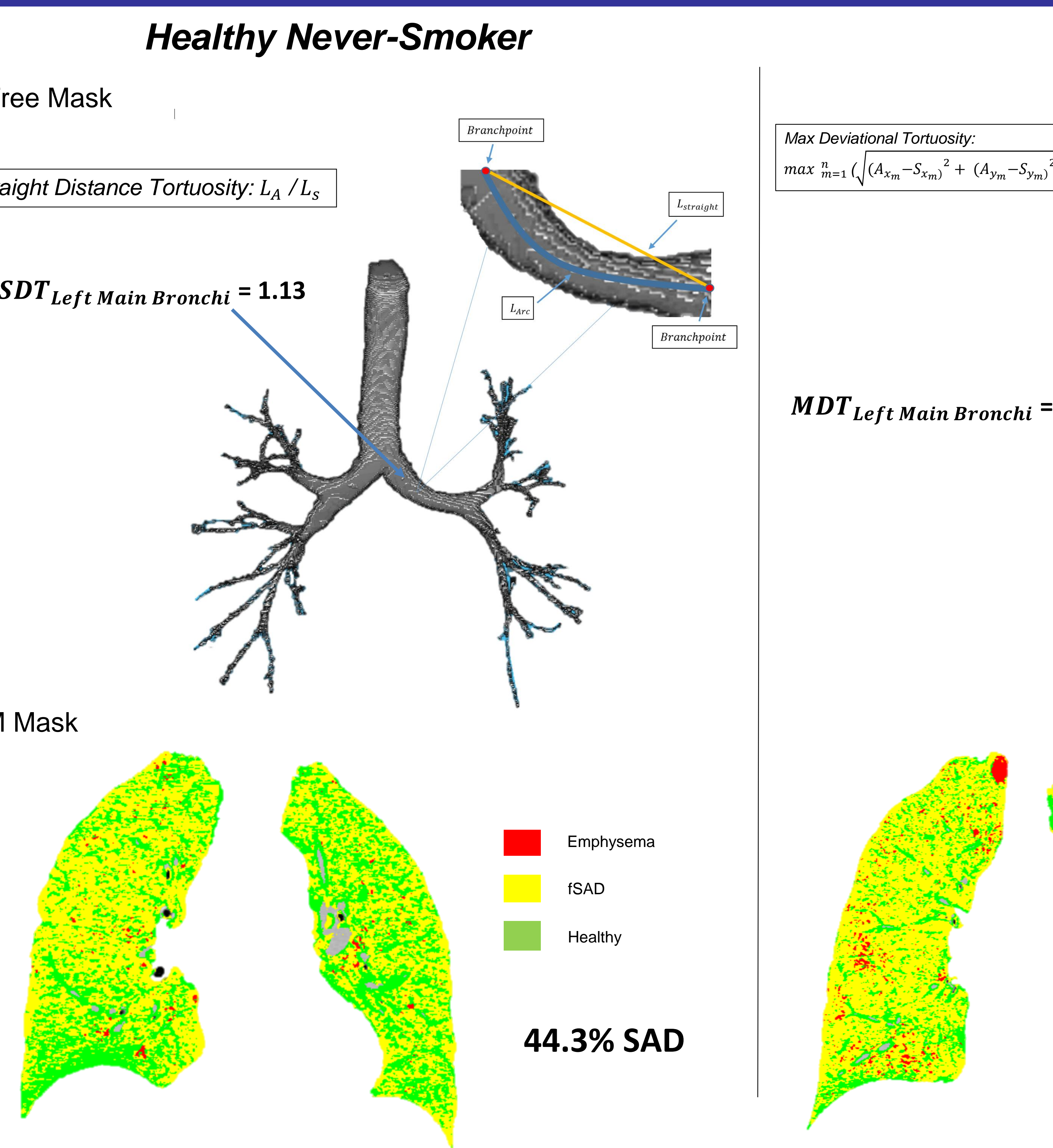

Mild COPD

Figure 1. 3D CT Airway Tree Segmentation and DPM Map for Never-smoker and Mild COPD Subject

Table 2. Multivariable Regression Models for fSAD including Average Sub-Segmental Deviational Tortuosity

\begin{tabular}{|c|c|c|c|}
\hline \multirow[b]{2}{*}{ Model } & \multicolumn{3}{|c|}{ All Variables } \\
\hline & $\begin{array}{l}\text { Standardized } \\
\text { Estimate }\end{array}$ & P-value & Variance Inflation Factor \\
\hline ISAD & & & \\
\hline Average Sub-Segmental Deviation & 0.10 & 0.02 & 1.13 \\
\hline Pi10 & -0.08 & 0.17 & 2.14 \\
\hline TAC & -0.17 & $<0.001$ & 1.60 \\
\hline Sub-Segmental Wall-Thickness & -0.012 & 0.89 & 5.00 \\
\hline Sub-Segmental Wall Area \% & 0.08 & 0.47 & 7.37 \\
\hline Sub-Segmental Lumen Area & -0.004 & 0.98 & 12.35 \\
\hline
\end{tabular}

Table 3. Multivariable Regression Models for fSAD in healthy, At Risk, and with COPD including Max SubSegmental Deviational Tortuosity

\begin{tabular}{|l|c|c|c|}
\multirow{2}{*}{ Model } & \multicolumn{3}{|c|}{ All Variables } \\
\cline { 2 - 4 } & $\begin{array}{c}\text { Standardized } \\
\text { Estimate }\end{array}$ & P-value & Variance Inflation Factor \\
\hline fSAD & & & \\
\hline Max Sub-Segmental Deviation & 0.09 & 0.047 & 1.15 \\
\hline Pi10 & -0.08 & 0.16 & 2.14 \\
\hline TAC & -0.17 & $<0.001$ & 1.63 \\
\hline Sub-Segmental Wall-Thickness & -0.007 & 0.94 & 7.98 \\
\hline Sub-Segmental Wall Area \% & 0.08 & 0.48 & 12.38 \\
\hline Sub-Segmental Lumen Area & -0.008 & 0.95 & \\
\hline
\end{tabular}

\section{Results Summary}

- Average, and max deviational tortuosity as well as straight distance tortuosity measurements were developed and investigated at the segmental and sub-segmental airway leve

- Significant associations were shown for sub-segmental average and max deviational tortuosity with DPM SAD using multivariate regression models which included standard quantitative CT airway morphological measurements

\section{Conclusions}

- CT airway tree tortuosity measurements are significantly and independently associated with small airway disease measurements in COPD

- This data supports the notion that morphometric measurements generated from the $3 \mathrm{D}$ airway tree segmentation can provide information related to the small airways, and therefore may replace the DPM SAD measurement

- Replacing DPM SAD would eliminate the need for both full-inspiration and full-expiration image acquisition, and therefore reduce dose to patients

\section{Future Directions}

The tortuosity of complete lobar and sub-lobar paths can be found and related to lobar and sub-lobar DPM SAD measurements

- Machine Learning algorithms can be applied to the extracted eatures to develop a model to predict likelihood of COPD development based on airway tree feature morphometry

\section{References}

[1] Ernst PP, Bourbeau J, Rainville B, Benayoun S, Suissa S. Underestimation of 2] Murray C., Lopez AD. Alternative projections of mortality and disability by cause 3] Mead J. The lung's "quiet zone." N Engl J Med : 1318-1319, 1970. 4] Kirby, M. et al. A Novel Method of Estimating Small Airway Disease Using inspiratory-to-Expiratory Computed Tomography. Respiration 94(4), 336-345 (2017).

\section{Acknowledgments}

We would like to thank all researchers, staff and subjects that are part of the CanCOLD study as well as our sponsors.

D.Genkin gratefully acknowledges support from the FEAS URO scholars program. 